\title{
Diclofenac predisposes benign prostate hyperplasia in fat feed albino rats
}

\author{
Moses Z. Zaruwa ${ }^{1 *}$, Halima S. Abdullahi ${ }^{1}$, Bawa Y. Muhammad ${ }^{1}$, Muhammad A. Ubana ${ }^{1}$, \\ Titilato O. Bamidele ${ }^{1}$, Ruqaiyat A. Muhammad ${ }^{2}$, Kingsley I. Ubaoji ${ }^{3}$
}

${ }^{1}$ Department of Biochemistry and Molecular Biology, Nasarawa State University, Keffi, Nigeria
${ }^{2}$ Department of Pharmacy, Federal Medical Centre Keffi, Nasarawa State, Nigeria
${ }^{3}$ Department of Applied Biochemistry, Nnamdi Azikiwe University, Awka, Anambra State, Nigeria

Received: 25 December 2021

Revised: 08 January 2022

Accepted: 10 January 2022

\section{*Correspondence:}

Dr. Moses Z. Zaruwa,

Email: mosesz.zaruwa@nsuk.edu.ng

Copyright: (c) the author(s), publisher and licensee Medip Academy. This is an open-access article distributed under the terms of the Creative Commons Attribution Non-Commercial License, which permits unrestricted non-commercial use, distribution, and reproduction in any medium, provided the original work is properly cited.

\begin{abstract}
Background: An attempt to establish the possible cause(s) of benign prostate hyperplasia (BPH) in fat feed albino rats treated with diclofenac (DCF)-potassium (K) was performed to ascertain its likely translational relationship in humans. Methods: Thirty-five male wistar albino rats of 24 weeks old were divided into five groups of 7 animals each were used. Group 1; the normal control (NC) was injected subcutaneously with the vehicle (olive oil) only and served normal diet. Group 2; standard group treated with testosterone propionate in olive oil ( $3 \mathrm{mg} / \mathrm{kg} \mathrm{b}$. wt.). Groups 3 , 4, and 5 were fed with the standard feed mixed with animal fat (sourced from roasted meat/condiments in aluminium foils) in 20, 40 and $80 \%$ portions, then treated with DCF-K in solution as low $(2 \mathrm{mg} / \mathrm{kg} \mathrm{b}$. wt.), mid (4 mg/kg b. wt.), and high (6 mg/kg b. wt.) doses, respectively. The blood samples collected were analysed for prostate specific antigen (PSA), hematological parameters, kidney and liver function.

Results: Group 3 showed the highest PSA elevation $(\mathrm{p}<0.05)$ when compared to the control and the untreated group. There was a significant elevation $(\mathrm{p}<0.05)$ in WBC levels compared to all other groups. PCV, MCV, NEUT, MONO and EOSIN levels increased significantly $(\mathrm{p}<0.05)$ across all groups. Significant $(\mathrm{p}<0.05)$ increase was observed in liver and kidney parameters compared to the untreated groups. Significant $(p<0.05)$ elevation in total cholesterol and LDL$\mathrm{C}$ levels across the groups was observed. The DCF-K treated groups showed increase in several parameters compared to the untreated groups.

Conclusions: It was obvious that fatty diet and use of DCF-K contributed to the observed hepatotoxicity, nephrotoxicity, hence predisposed tissue damage and inflammation which conjunctly elevated PSA.
\end{abstract}

Keywords: Diclofenac, Fat, Hepatotoxicity, Haematology, PSA

\section{INTRODUCTION}

Some ailments have been observed over time to affect one male more than the other. This is linked mainly to nature among which are climate, culture, nutrition, drug use etc. The ailment of interest in this study is BPH. BPH has been observed to affect black men more than it does other races. ${ }^{1}$ Previous studies in the USA showed that middle to advanced aged men of Negro decent are prone to BPH than those of Caucasian decent. ${ }^{2}$ Native African communities too are known to have a high prevalence of $\mathrm{BPH}$, though this knowledge is a result of increase in awareness, since African men now open up to air such problems. ${ }^{3,4}$ Death rate from specific ailments in small communities sends scare message or creates concern among its people. The fact that most African governments tend to ignore health 
concerns of its people, by not prioritizing primary to advance healthcare in such countries contributed to the concerns about ailments such as BPH or related diseases. ${ }^{5}$

Having ruled out several possible predisposer of BPH in our local communities and environs, such as food, alcohol etc, we focused on malaria treatment as a likely predisposing factor, with emphasis on diclofenac (pain killer or analgesic) and artemether/lumefantrine, which are the main treatment used for malaria.

BPH and related ailments are among several diseases responsible for discomfort and death among adult males. This research attempted to find the possible cause(s) of the ailment. The consumption of roasted meat (Suya) in places of recreation or relaxation was scrutinized and the biochemical evaluation of the abuse of Diclofenac (DCF)potassium (K) a non-steroidal anti-inflammatory drug (NSAID) was performed with intent to establish if it predisposes BPH in rats when fed with fatty diet. The average life-style of most men age between 45 and above was put into consideration which necessitated the idea of feeding the experimental rats with fatty foods apart from another group which was fed with normal rat chow. ${ }^{6}$

The main aim of this research therefore, is to evaluate the possible effect of DCF-K in rat models which were well fed with fatty diet, hence mimicking the average male who eats lots of meat and alcohol as a past time or relaxation in typical Nigerian community.

\section{METHOD}

DCF-K $50 \mathrm{mg}$, testosterone propionate injection, olive oil, diethyl ether P-nitro-phenyl phosphate, buffer solution for ALP containing $0.5 \mathrm{mmol}$ magnesium chloride, 2,4dinitrophenyl hydrazine, buffer solution containing 100 $\mathrm{mmol} / \mathrm{L}$ phosphate buffer, monoclonal anti-free PSA alkaline phosphate, standard cholesterol reagents, standard triglycerides, phosphor-tungstate and magnesium chloride.

\section{Experimental design and animal treatment}

Thirty-five male Wistar albino rats, 24 weeks old were purchased from national veterinary research institute (NVRI), Vom. Plateau state, Nigeria. They were kept in the animal house of the department of biochemistry, Nasarawa State university, Keffi; with proper ventilation condition and 12 hours day light as well as 12 hours dark night cycle. The rats were weighed and divided into five groups of 7 animals each and acclimatized for two weeks before the experiment commenced. Group 1; the normal control (NC) was injected subcutaneously with the vehicle (olive oil) only and fed normal animal chow. Group 2; standard group treated with testosterone propionate in olive oil ( $3 \mathrm{mg} / \mathrm{kg} \mathrm{b} \mathrm{wt})$. Groups 3, 4, and 5 were fed with the standard feed mixed with animal fat (sourced from roasted meat/condiments in aluminium foils) in 20, 40 and $80 \%$ portions, then treated with DCF-K in solution as low
( $2 \mathrm{mg} / \mathrm{kg} \mathrm{b} \mathrm{wt),} \mathrm{mid} \mathrm{(4} \mathrm{mg/kg} \mathrm{b} \mathrm{wt.),} \mathrm{and} \mathrm{high} \mathrm{(} 6 \mathrm{mg} / \mathrm{kg} \mathrm{b}$ wt.) doses, respectively. The experiment lasted for 12 weeks March 2020-June, 2021.

\section{Animal sacrifice and blood sample collection}

The rats were allowed to fast overnight and sacrificed under mild euthanasia with pentobarbital. Blood samples were collected by cardiac puncture into plain, and EDTA bottles, respectively for chemistry and haematological assays. The blood was allowed to clot in plain bottles and the serum separated at 3500 RPM for 15 min then used for the determination of PSA, kidneys and liver functions.

\section{Determination of serum PSA}

The serum PSA levels were evaluated with a PSA ELISA kit according to the manufacturer's instructions (Rapid labs. Ltd, Colchester, Essex, UK). The absorbance was measured at $450 \mathrm{~nm}$ using a microplate reader (Bio-Rad laboratories, Inc.). The values were expressed as ng protein mg.

\section{Biochemical analysis}

Biochemical evaluation was performed to determine liver function (serum concentrations of AST, ALT, ALP, conjugated and total bilirubin), kidney function (urea, creatinine and electrolytes) using automated biochemical analyser. While kits (Bio-Rad company), were used to assay for lipid profile (Total cholesterol, VLDL, LDL and HDL) according to manufacturer's direction.

\section{Statistical analysis}

One-way analysis of variance was used in analysing the results using the predictive analytics software (International business machines (IBM), United States) statistics 18 package. All the results were expressed as mean \pm standard error and $\mathrm{p}<0.05$ were considered significant.

\section{RESULTS}

Table 1: Effect of diclofenac on PSA levels in BPH rat models.

\begin{tabular}{|ll|}
\hline Groups & PSA $(\mathrm{ng} / \mathrm{ml})$ \\
\hline Group 1 & $0.10 \pm 0.00^{\mathrm{a}}$ \\
\hline Group 2 & $0.48 \pm 0.17^{\mathrm{c}}$ \\
\hline Group 3 & $1.43 \pm 0.30^{\mathrm{d}}$ \\
\hline Group 4 & $0.54 \pm 0.30^{\mathrm{c}}$ \\
\hline Group 5 & $0.68 \pm 0.12^{\mathrm{c}}$ \\
\hline
\end{tabular}

Results are expressed in means \pm SD $(6=4)$. Mean values with different letters as superscripts down the rows are considered significant at $\mathrm{p}<0.05$, group $1=$ negative control (treated with vehicle), group $2=$ testosterone treated, group $3=$ low dose + fat feed, group 4=Middle dose + fat feed, group 5=High dose + fat feed. 
Table 2: Effect of diclofenac on hematological parameters in BPH induced rat models.

\begin{tabular}{|c|c|c|c|c|c|c|}
\hline Groups & WBC $\left(10^{9 / 1} \mathrm{~g} / \mathrm{l}\right)$ & $\operatorname{RBC}\left(10^{12 / 1} \mathrm{~g} / \mathrm{l}\right)$ & HB (g/dl) & PCV (\%) & MCV (FL) & PLT $\left(10^{9 / 1} \mathrm{~g} / \mathrm{l}\right)$ \\
\hline 1 & $6.30 \pm 0.89^{b}$ & $6.00 \pm 0.04^{c}$ & $23.87 \pm 0.75^{\mathrm{h}}$ & $19.77 \pm 0.41^{\mathrm{m}}$ & $76.10 \pm 2.03^{t}$ & $253.33 \pm 2.03^{w}$ \\
\hline 2 & $149.00 \pm 0.10^{\mathrm{a}}$ & $6.20 \pm 0.08^{c}$ & $20.87 \pm 0.21^{\mathrm{h}}$ & $21.10 \pm 0.61^{\mathrm{m}}$ & $68.92 \pm 0.61^{t}$ & $199.50 \pm 0.61^{x}$ \\
\hline 3 & $9.05 \pm 0.77^{c}$ & $3.75 \pm 0.12^{\mathrm{g}}$ & $12.70 \pm 0.81^{\mathrm{j}}$ & $33.55 \pm 1.17^{\mathrm{s}}$ & $151.72 \pm 58.48^{v}$ & $247.37 \pm 52.66^{\alpha}$ \\
\hline 4 & $6.30 \pm 0.89^{c}$ & $3.35 \pm 0.28^{\mathrm{g}}$ & $11.10 \pm 0.81^{\mathrm{j}}$ & $33.15 \pm .36^{\mathrm{s}}$ & $98.05 \pm .69^{u}$ & $179.25 \pm 17.55^{z}$ \\
\hline 5 & $6.70 \pm 0.40^{c}$ & $3.65 \pm 0.36^{\mathrm{g}}$ & $18.37 \pm 7.13^{1}$ & $33.60 \pm .81^{\mathrm{s}}$ & $100.30 \pm 2.28^{u}$ & $194.00 \pm 26.12^{z}$ \\
\hline
\end{tabular}

Results are expressed in means \pm SD $(6=4)$. Mean values with different letters as superscripts down the rows are considered significant at $\mathrm{p}<0.05$, group $1=$ negative control (treated with vehicle), group $2=$ testosterone treated, group $3=$ low dose + fat feed, group $4=$ middle dose + fat feed, group $5=$ high dose + fat feed.

Table 3: Effect of diclofenac on differential cell count in BPH induced rat models.

\begin{tabular}{|lllll|}
\hline Groups & NEUT $(\%)$ & LYMP $(\%)$ & MONO $(\%)$ & EOSIN $(\%)$ \\
\hline $\mathbf{1}$ & $21.50 \pm 0.61^{\mathrm{a}}$ & $71.00 \pm 0.81^{\mathrm{d}}$ & $4.50 \pm 0.20^{\mathrm{g}}$ & $3.00 \pm 0.00^{\mathrm{h}}$ \\
\hline $\mathbf{2}$ & $49.50 \pm 0.21^{\mathrm{b}}$ & $41.00 \pm 0.42^{\mathrm{e}}$ & $6.50 \pm 0.20^{\mathrm{g}}$ & $3.00 \pm 0.00^{\mathrm{h}}$ \\
\hline $\mathbf{3}$ & $48.00 \pm 2.44^{\mathrm{b}}$ & $45.00 \pm 4.08^{\mathrm{e}}$ & $4.45 \pm 1.22^{\mathrm{g}}$ & $2.50 \pm 4.00^{\mathrm{h}}$ \\
\hline $\mathbf{4}$ & $54.00 \pm 8.10^{\mathrm{b}}$ & $39.50 \pm 1.22^{\mathrm{e}}$ & $4.45 \pm 1.22^{\mathrm{g}}$ & $2.00 \pm .8 .10^{\mathrm{h}}$ \\
\hline $\mathbf{5}$ & $45.00 \pm 4.08^{\mathrm{b}}$ & $41.50 \pm 9.38^{\mathrm{e}}$ & $5.95 \pm 4.08^{\mathrm{g}}$ & $6.00 \pm 1.63^{\mathrm{l}}$ \\
\hline
\end{tabular}

Results are expressed in means \pm SD $(6=4)$. Mean values with different letters as superscripts down the rows are considered significant at $\mathrm{p}<0.05$, group $1=$ negative control (treated with vehicle), group $2=$ testosterone treated, group $3=$ low dose + fat feed, group $4=$ middle dose + fat feed, group $5=$ High dose + fat feed.

Table 4: Effect of diclofenac on liver function parameters in BPH induced rat models.

\begin{tabular}{|llllll|l|}
\hline Groups & Total bil. $(\mu \mathrm{mol} / \mathrm{L})$ & Conjugated bil. $(\mu \mathrm{mol} / \mathrm{L})$ & ALP $^{\mathrm{a}}$ (IU/L) & ALT (IU/L) & AST (IU/L) \\
\hline $\mathbf{1}$ & $3.30 \pm 0.08^{\mathrm{a}}$ & $0.35 \pm 0.10^{\mathrm{c}}$ & $197.10 \pm 13.02^{\mathrm{g}}$ & $80.00 \pm 0.28^{\mathrm{i}}$ & $53.00 \pm 0.43^{\mathrm{m}}$ \\
\hline $\mathbf{2}$ & $3.30 \pm 0.04^{\mathrm{a}}$ & $1.35 \pm 0.02^{\mathrm{d}}$ & $196.00 \pm 21.43^{\mathrm{g}}$ & $210.00 \pm 25.2^{\mathrm{j}}$ & $210.00 \pm 25.12^{\mathrm{o}}$ \\
\hline $\mathbf{3}$ & $5.35 \pm 2.49^{\mathrm{b}}$ & $2.45 \pm 0.93^{\mathrm{f}}$ & $245.20 \pm 32.41^{\mathrm{h}}$ & $72.60 \pm 20.08^{\mathrm{i}}$ & $120.25 \pm 55.64^{\mathrm{n}}$ \\
\hline $\mathbf{4}$ & $6.15 \pm 0.20^{\mathrm{b}}$ & $3.00 \pm 0.16^{\mathrm{e}}$ & $194.60 \pm 3396^{\mathrm{g}}$ & $69.50 \pm 13.79^{\mathrm{i}}$ & $59.50 \pm 8.32^{\mathrm{m}}$ \\
\hline $\mathbf{5}$ & $5.40 \pm 0.65^{\mathrm{b}}$ & $2.30 \pm 0.40^{\mathrm{f}}$ & $251.75 \pm 38.90^{\mathrm{h}}$ & $59.70 \pm 2.77^{\mathrm{i}}$ & $65.95 \pm 16.37^{\mathrm{m}}$ \\
\hline
\end{tabular}

Results are expressed in means \pm SD $(6=4)$. Mean values with different letters as superscripts down the rows are considered significant at $\mathrm{p}<0.05$, group $1=$ negative control (treated with vehicle), group $2=$ testosterone treated, group $3=$ Low dose + fat feed, group $4=$ middle dose + fat feed, group 5=High dose + fat feed.

Table 5: Effect of diclofenac on kidney function in BPH induced rat models.

\begin{tabular}{|lllllll|} 
Groups & $\begin{array}{l}\mathbf{N a}^{+} \\
(\mathbf{m m o l} / L)\end{array}$ & $\begin{array}{l}\mathrm{K}^{+} \\
(\mathbf{m m o l} / \mathrm{L})\end{array}$ & $\begin{array}{l}\mathrm{Cl}^{-} \\
(\mathbf{m m o l} / \mathrm{L})\end{array}$ & $\begin{array}{l}\mathrm{HCO}_{3}{ }^{-} \\
(\mathbf{m m o l} / \mathrm{L})\end{array}$ & $\begin{array}{l}\text { Urea } \\
(\mathbf{m m o l} / \mathrm{L})\end{array}$ & $\begin{array}{l}\text { Creatinine } \\
(\mathbf{m m o l} / \mathrm{L})\end{array}$ \\
\hline $\mathbf{1}$ & $151.42 \pm 0.16^{\mathrm{a}}$ & $3.00 \pm 0.04^{\mathrm{c}}$ & $103.87 \pm 0.18^{\mathrm{g}}$ & $19.77 \pm 0.14^{\mathrm{k}}$ & $5.67 \pm 0.06^{\mathrm{n}}$ & $76.10 \pm 0.04^{\mathrm{r}}$ \\
\hline $\mathbf{2}$ & $149.00 \pm 0.53^{\mathrm{a}}$ & $3.20 \pm 0.16^{\mathrm{c}}$ & $100.87 \pm 0.14^{\mathrm{g}}$ & $21.10 \pm 0.81^{\mathrm{k}}$ & $6.62 \pm 0.57^{\mathrm{n}}$ & $68.92 \pm 1.86^{\mathrm{r}}$ \\
\hline $\mathbf{3}$ & $151.15 \pm 0.36^{\mathrm{a}}$ & $10.60 \pm 2.20^{\mathrm{d}}$ & $102.25 \pm 0.28^{\mathrm{g}}$ & $19.25 \pm 0.53^{\mathrm{l}}$ & $7.25 \pm 1.18^{\mathrm{n}}$ & $88.88 .30 \pm 15.02^{\mathrm{s}}$ \\
\hline $\mathbf{4}$ & $124.40 \pm 19.10^{\mathrm{b}}$ & $11.35 \pm 3.06^{\mathrm{e}}$ & $102.85 \pm 0.04^{\mathrm{j}}$ & $24.60 \pm 9.74^{\mathrm{m}}$ & $13.70 \pm 1.06^{\mathrm{o}}$ & $71.50 \pm 2.36^{\mathrm{r}}$ \\
$\mathbf{5}$ & $150.45 \pm 0.53^{\mathrm{a}}$ & $8.65 \pm 0.53^{\mathrm{b}}$ & $102.35 \pm 0.20^{\mathrm{h}}$ & $13.80 \pm 0.65^{\mathrm{l}}$ & $8.85 \pm 2.08^{\mathrm{p}}$ & $75.40 \pm 5.14^{\mathrm{r}}$ \\
\hline
\end{tabular}

Results are expressed in Means \pm SD $(6=4)$. Mean values with different letters as superscripts down the rows are considered significant at $\mathrm{p}<0.05$, group $1=$ Negative control (treated with vehicle), group $2=$ testosterone treated, group $3=$ Low dose + fat feed, group $4=$ Middle dose + fat feed, group $5=$ High dose + fat feed.

Table 6: Effect of diclofenac on lipid profile status of BPH induced rat models.

\begin{tabular}{|lllll|} 
Groups & Total cholesterol $(\mathbf{m m o l} / \mathrm{L})$ & HDL $(\mathbf{m m o l} / \mathrm{L})$ & TG $(\mathbf{m m o l} / \mathrm{L})$ & LDL $(\mathbf{m m o l} / \mathrm{L})$ \\
$\mathbf{1}$ & $1.10 \pm 0.00^{\mathrm{a}}$ & $0.50 \pm 0.04^{\mathrm{e}}$ & $0.90 \pm 0.04^{\mathrm{i}}$ & $0.40 \pm 0.04^{\mathrm{m}}$ \\
$\mathbf{2}$ & $1.30 \pm 0.00^{\mathrm{a}}$ & $0.48 \pm 0.06^{\mathrm{e}}$ & $0.70 \pm 0.08^{\mathrm{l}}$ & $0.50 \pm 0.00^{\mathrm{m}}$ \\
\hline $\mathbf{3}$ & $2.20 \pm 0.32^{\mathrm{c}}$ & $0.35 \pm 0.04^{\mathrm{e}}$ & $0.10 \pm 0.08^{\mathrm{k}}$ & $2.80 \pm 1.00^{\mathrm{n}}$ \\
\hline $\mathbf{4}$ & $2.30 \pm 0.40^{\mathrm{c}}$ & $0.45 \pm 0.04^{\mathrm{e}}$ & $0.70 \pm 0.00^{\mathrm{l}}$ & $1.25 \pm 0.12^{\mathrm{p}}$ \\
$\mathbf{5}$ & $1.70 \pm 0.24^{\mathrm{b}}$ & $0.40 \pm 0.16^{\mathrm{e}}$ & $0.70 \pm 0.00^{\mathrm{l}}$ & $1.45 \pm 0.04^{\mathrm{o}}$ \\
\hline
\end{tabular}

Results are expressed in means \pm SD $(6=4)$. Mean values with different letters as superscripts down the rows are considered significant at $\mathrm{p}<0.05$, group $1=$ Negative control (treated with vehicle), group $2=$ Testosterone treated, group $3=$ Low dose + fat feed, group $4=$ Middle dose + fat feed, group $5=$ High dose + fat feed. 


\section{DISCUSSION}

The biochemical evaluation of the drug DCF-K a nonsteroidal anti-inflammatory drug (NSAID) was performed with intent to establish if it predisposes BPH in rats when fed with fatty diet. This was so, to mimic the life style of middle-class men in Keffi, Nigeria whom while on leisure sit outs would often drink alcohol alongside roasted meat at local bars or sit-outs.

In this study, DCF-K exhibited significant $(\mathrm{p}<0.05)$ alterations in PSA values across the groups. The group (Group 3) fed with 20\% fat showed the highest PSA levels compared to the standard group (group 2) with about three folds and thirteen folds difference in normal uninduced/untreated group (Group 1). The PSA levels obtained is evident that DCF had negative effect on the prostate gland leading to higher PSA secretions. In our previous article, we had postulated that DCF possibly predisposes $\mathrm{BPH}$, because it was suspected that there is increased generation of free radicals after ingesting DCF, which in turn exacerbated inflammatory response and other cellular processes, hence initiated the promotion and progression of abnormal cell proliferation, enlargement and possible neoplasms which may lead to cancer. ${ }^{6}$ Comparatively, the PSA levels obtained here showed a clear cut difference, as these animals fed with fats exhibited slightly lower PSA levels. The reason behind the difference in PSA value still remains unclear but noting that, animal fat is consumed alongside some condiments that have been observed to possess strong hypolipidemic properties may be responsible for the decreased level of PSA. ${ }^{7,8,9}$

Testosterone injection showed a sharp alteration in haematological parameters (Table 2). The WBC level increased by about twenty-four-fold compared with the untreated group). The increase in WBC level could be said to result to significant neutropenia and lymphocytosis during the study period probably due to immune modulatory effects. Increased WBC counts occur as a result of an infection, cancer, or presence of xenobiotics in the blood. ${ }^{10}$ The decreases in RBC, HB counts observed in our study may therefore be attributed to the decrease in feeds consumption, due to the enervating effects of the drug. The effect could have an interplay between the fatty acids/lipids and the natural antioxidants which accompanied it during ingestion by the rats. ${ }^{11}$

The decrease in RBC, HB and increase in WBC by DCF$\mathrm{K}$ was previously reported. ${ }^{12}$ Testosterone promotes the differentiation of hematopoietic progenitors into the myeloid lineage as indicated in human trials. ${ }^{13}$ The decrease in some blood parameters caused by this drug may be attributed to its harmful effects on bone marrow and haematopoietic organs. ${ }^{14}$ The HB, PCV and MCV levels all showed varying alterations in Table 5. The platelets levels was shown to be high in group 1 and 3 when compared to other groups, which indicated that at low concentration of DCF-K the platelets levels increased.
The dietary fat and accompanying xenobiotics may be responsible for a reversal of these observations. ${ }^{6}$ It supports the view that, although DCF-K is an antiinflammatory drug at low dose, it has negative effect at very high concentration by inducing inflammatory process. ${ }^{15}$ The elevation in WBC was only significant in testosterone group.

The effect of DCF-K on lipid profile agrees with studies using human beings and dogs in which significant $(p<0.05)$ elevation was observed in concentration across the treated groups. ${ }^{16}$ The increase in total cholesterol level across the treated groups (BPH model) is indicative of the life styles of individuals with regards to $\mathrm{BPH} .{ }^{17}$ The observed increase was probably as a result of DCF-K effect on the liver; leading to hepato-biliary impairment as evident by the significant increase in serum liver enzymes (ALT and AST) and certainly as a result of high fat intake and the debilitating effect of the DCF-K on the concerned organ. This phenomenon must have hindered or obstructed the transport of triglycerides from the hepatocytes, thus rendering lower amounts of triglycerides in the serum. ${ }^{18}$ Noting that, the liver is the vital tissue of lipid metabolism, drug-induced liver impairment raised total cholesterol levels, while HDL-cholesterol levels decreased alongside those of triglycerides but raised LDL-cholesterol because of the fat intake, respectively. ${ }^{19}$ The implication of these findings points to DCF-K interaction with dietary xenobiotic, thus led to the generation of ROS and RNS which undoubtedly enhanced oxidative stress in several pathophysiological conditions, including the prostate gland hence to $\mathrm{BPH} .{ }^{18}$ There is no doubt therefore, that the examined lifestyle of men who are into leisure with alcohol and high fat diets such as roasted meat may be predisposed to $\mathrm{BPH}$.

A previous report on DCF-K induced rats showed kidney and liver function aberrations. ${ }^{14}$ DCF-K effect on renal function showed that, it impaired urinary output within 10 minutes of its administration by injection in humans. ${ }^{20} \mathrm{It}$ was observed that, this effect was as a result of the inhibition of prostaglandin (PG) synthesis in animals and PG is a part of prostatic secretion. ${ }^{21}$ There is no doubt therefore that, DCF-K negatively affects the prostate gland. It is equally known that PGs are synthesized at sites of tissue damage or infection, where it causes inflammation and pain. The prostate gland by its nature as a soft tissue, is vulnerable and therefore linked up with the prediction that DCF-K metabolites are likely toxic to the gland. A study had suggested earlier that DCF-K causes muscle contraction in the uterus and that higher concentration were linked to menstrual cramps caused by endometriosis. ${ }^{22}$ This claim supports our deduction of the negative effect of DCF-K on the soft tissues like the prostate gland.

The biochemical markers evaluated in the rats for DCF-K effect on liver function, showed alterations in total bilirubin, conjugate bilirubin, ALP, AST and ALT. The other groups (3-5) however, showed significantly $(\mathrm{p}<0.05)$ 
higher enzyme concentrations, probably triggered by the interaction between DCF-K and dietary xenobiotics. It justified the claim of hepatotoxicity in rats by DCF-K in a dose dependent pattern. ${ }^{23}$ The biomarkers in the kidney studies showed significant alterations in urea and creatinine levels, as well as $\mathrm{K}^{+}$concentration. Urea and creatinine are excreted solely through the kidney; however, damage to the kidney will inhibit excretion, resulting in their accumulation in the blood.

Our study is consistent with earlier reports that showed increased levels of serum creatinine and urea in mice exposed to DCF-K. ${ }^{14}$ These are indications of acute kidney injury (AKI). It is obvious that AKI increases the free radical levels within the system, which tends to cause inflammation of various organs and especially very soft tissues such as the prostate gland. ${ }^{24}$ The condiments contained in the fatty diet were certainly of little benefits to the rat models considering the pathological damages observed during the study.

In this study limitations was the inability to determine reactive oxygen species so as ascertain tissue damage.

\section{CONCLUSION}

From the results obtained in this research, we concluded that fatty diet and exposure to DCF-K led to hepatotoxicity, nephrotoxicity and predisposed some forms of tissue damage and inflammation which conjunctly elevated PSA a prime marker of BPH/E.

Funding: No funding sources

Conflict of interest: None declared

Ethical approval: The study was approved by the Institutional Ethics Committee

\section{REFERENCES}

1. Antoine SG, Carmichael H, Lloyd GL. The Impact of Race, Ethnicity and Insurance Status on Surgery Rates for Benign Prostatic Hyperplasia. Urology. 2021;05:092.

2. Rundle AG, Sadasivan SM, Chitale DA, Gupta NS, Williamson SR, Kryvenko ON et al. Racial differences in the systemic inflammatory response to prostate cancer. Plos one. 2021;16(7):e0252951.

3. Gudaru K, Gonzalez Padilla DA, Castellani D, Tortolero Blanco L, Tanidir Y, Ka Lun L et al. A global knowledge, attitudes and practices survey on anatomical endoscopic enucleation of prostate for benign prostatic hyperplasia among urologists. Andrologia. 2020;52(8):e13717.

4. Mbugua RG, Oluchina S, Karanja. Prostate cancer awareness and screening among men in a rural community in Kenya: a cross-sectional study. Afr J Urol. 2021;27:(7):2-10.

5. Neimark BD, Tilghman LM. Bioprospecting a biodiversity hotspot: the political economy of natural products drug discovery for conservation goals in
Madagascar. In Conservation and environmental management in Madagascar, Routledge. 2014;295322.

6. Zaruwa MZ, Muhammad YB, Abdullahi HS, Ubana MA, Ubaoji KI, Adamu RM. Evaluation of Diclofenac (DCF) Potassium as a Possible Predisposer of Benign Prostatic Hyperplasia in Wistar Albino Rats. Saudi J Biomed Res. 2020;8(5):243-8.

7. Yashin A, Yashin Y, Xia X, Nemzer B. Antioxidant activity of spices and their impact on human health. A review. Antioxidant. 2017;6(3):70:1-18.

8. Masroor A, Amir RM, Komal F, Nasri MA. Efficacy study of ginger and garlic mixture on hypolidemic and hyperlipidemic parameters of induced diabetic mice. Int J Biosci. 2017;10(1):374-81.

9. Vidyavati HG, Hanumanthappa M, Hamavathy J, Srinivasan K. Hypolipidemic and antioxidant efficacy of dehydrated onion in experimental rats. J Food Sci Technol. 2010;47(1):55-60.

10. Mazzone P, Tierney W, Hossain M, Puvenna V, Janigro D, Cucullo L. Pathophysiological impact of cigarette smoke exposure on the cerebrovascular system with a focus on the blood-brain barrier: expanding the awareness of smoking toxicity in an underappreciated area. Int J Environmental Res Public health. 2010;7(12):4111-26.

11. Biondo PD, Brindley DN, Sawyer MB, Field CJ. The potential for treatment with dietary long-chain polyunsaturated n-3 fatty acids during chemotherapy. J Nutritional Biochem. 2010;19(12):787-96.

12. Vargas-Sánchez K, Garay-Jaramillo E, GonzálezReyes RE. Effects of Moringa oleifera on glycaemia and insulin levels: A Review of animal and human studies. Nutrients. 2019;11(12):2907.

13. Gagliano-Jucá T, Pencina KM, Guo W, Li Z, Huang G, Basaria S, Bhasin S. Differential effects of testosterone on circulating neutrophils, monocytes, and platelets in men: Findings from two trials. Andrology. 2020;8(5):1324-31.

14. Aycan İÖ, Elpek Ö, Akkaya B, Kıraç E, Tuzcu H, Kaya S, Aslan M. Diclofenac induced gastrointestinal and renal toxicity is alleviated by thymoquinone treatment. Food Chem Toxicol. 2018;118:795-804.

15. Parolini M. Toxicity of the Non-Steroidal AntiInflammatory Drugs (NSAIDs) acetylsalicylic acid, paracetamol, diclofenac, ibuprofen and naproxen towards freshwater invertebrates: A review. Science Total Environment. 2010;740:140043.

16. Keeley TP, Mann GE. Defining physiological normoxia for improved translation of cell physiology to animal models and humans. Physiological reviews. 2019;99(1):161-234.

17. Besiroglu H, Dursun M, Otunctemur A, Ozbek E. The association between triglyceride high density lipoprotein cholesterol ratio and benign prostate hyperplasia in non-diabetic patients: a cross-sectional study. Aging Male. 2017;20(3):198-204.

18. Motawi TK, Ahmed SA, El-Boghdady NA, Metwally NS, Nasr NN. Impact of betanin against paracetamol 
and diclofenac induced hepato-renal damage in rats. Biomarkers. 2020;25(1):86-93.

19. Lagathu C, Béréziat V, Gorwood J, Fellahi S, Bastard JP, Vigouroux $\mathrm{C}$ et al. Metabolic complications affecting adipose tissue, lipid and glucose metabolism associated with HIV antiretroviral treatment. Expert opinion on drug safety. 2019;18(9):829-40.

20. Sivaraj R, Umarani S. Diclofenac-induced biochemical changes in nephrotoxicity among male Albino rats. Int J Basic Clin Pharmacol. 2018;7:6403.

21. Jin R, Strand DW, Forbes CM, Case T, Cates JM, Liu $\mathrm{Q}$ et al. The prostaglandin pathway is activated in patients who fail medical therapy for benign prostatic hyperplasia with lower urinary tract symptoms. The Prostate. 2021;81(13):944-55.

22. Vallina JRP, Cantabrana B, Sanchez M, Hidalgo A. Involvement of sodium/calcium exchange in the diclofenac-induced spasmolytic effect on rat uterus. General pharmacol. 1995;26(6):1249-53.
23. Sánchez S, De La Lastra CA, Ortiz P, Motilva V, Martín MJ. Gastrointestinal tolerability of metamizol, acetaminophen, and diclofenac in subchronic treatment in rats. Digestive Dis Sci. 2002;47(12):2791-8.

24. Zeng M, Qi M, Wang Y, Xu R, Wu Y, Li M et al. 5$\mathrm{O}$-methyldihydroquercetin and cilicicone $\mathrm{B}$ isolated from Spina Gleditsiae ameliorate lipopolysaccharideinduced acute kidney injury in mice by inhibiting inflammation and oxidative stress via the TLR4/MyD88/TRIF/NLRP3 signalling pathway. Int Immunopharmacol. 2020;80:106194.

Cite this article as: Zaruwa MZ, Abdullahi HS, Muhammad BY, Ubana MA, Bamidele TO,

Muhammad RA et al. Diclofenac predisposes benign prostate hyperplasia in fat feed albino rats. Int $\mathbf{J}$ Basic Clin Pharmacol 2022;11:80-5. 